At present, only the racemic forms of laudanosine and of tetrahydropapaverine have been employed in preparing compound 20 . Work on the resolution of laudanosine is now in progress, and in due course we hope to investigate the properties of the bis quaternary ammonium salts prepared from the stereoisomers.

We wish to express our thanks to Mr. W. C. Austin for help in the chemical work, and to Miss M. P. Hatton and Mr. R. A. Hall for help in the pharmacological work. We also wish to thank the directors of Allen and Hanburys, Ltd., for permission to publish this communication.

E. P. TAYLOR

H. O. J. COLLIER

Research Division,

Allen and Hanburys, Ltd.

Ware, Herts. Jan. 22.

${ }^{1}$ Taylor, E. P., and Collier, H. O. J., Nature, 165, 602 (1950).

${ }^{2}$ Crajg, L. E., and Tarbell, D. S., J. Amer. Chem. Soc., 70, 2783 (1948).

${ }^{3}$ Paton, W. D. M., and Zaimis, E. J., Brit. J. Pharmacol., 4, 381 (1949).

\section{Specificity of the Enzyme Aconitase}

Because the enzyme named 'aconitase'1 catalyses the conversion of cis-aconitate both to citrate and to isocitrate (and the reverse reactions), it has been thought ${ }^{2}$ that it may be a mixture of two enzymes, though Buchanan and Anfinsen ${ }^{3}$ found no evidence of this.

As in the ease of hydration of fumarate to malate ${ }^{4}$, it is necessary to assume that $\mathrm{H}_{2} \mathrm{O}$ is added exclusively to one member of the double bond of cis. aconitate, in order to explain the formation of optically active products. This necessitates, in both cases, the assumption of a 'three-point attachment' of the substrate to the enzymes. The formation of citrate or isocitrate depends only on the direction of addition of $\mathrm{H}_{2} \mathrm{O}$.

Now it is not necessary to assume that there is any preferred direction of addition of $\mathrm{H}_{2} \mathrm{O}$ to fumarate (relative to the asymmetric enzyme), since addition in either direction (see formulæ) yields the same

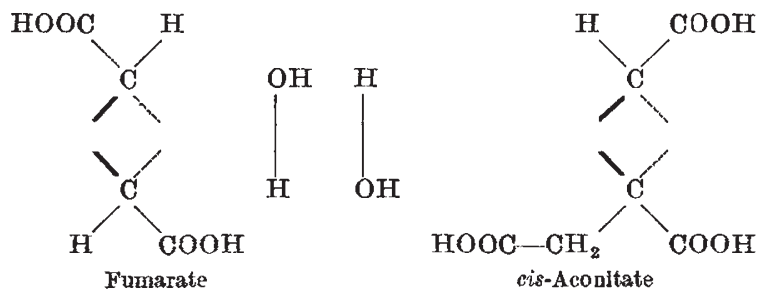

isomer of malate. This makes it likely that with $c i s$-aconitate also there is no preferred direction and, thence, that citrate and isocitrate may be formed by the action of a single enzyme. It is of interest that Martius and Lynen ${ }^{6}$ have shown that the initial rates of formation of citrate and isocitrate are approximately equal. The occurrence of the reverse reactions follows from the requirement of catalytic reversibility.

Department of Biochemistry, Oxford. Dec. 12

${ }^{1}$ Martius, C., and Knoop, F., Z. physiol. Chem., 246, 1 (1937). ${ }^{2}$ Jacobsohn, K. P., and Tapadinhas, J., Enzymologia, 5, 388 (1938).

${ }^{3}$ Buchanan, J. M., and Anfinsen, C. B., J. Biol. Chem., 180, 47 (1949).

'Krebs, H. A., Harvey Lectures, Series xliv, 165 (1950).

Ogston, A. G., Nature, 162, 963 (1948).

"Martius, C., and Iynen, F., "Advances in Enzymology", 10, 190 (1950).

\section{Formation of Hydroxylamine from Amino- Compounds in Aqueous Solution by Irradi- ation with X-Rays}

IN recent studies of the effects of ionizing radiations on aqueous solutions of compounds containing amino-groups such as, for example, amino-acids ${ }^{1}$, adenine ${ }^{2}$, nucleic acids ${ }^{2,3}$, it has been shown that, among other changes, ammonia is formed. In the case of the nueleic acids, for example, the ammonia arises from the constituent purine and pyrimidine bases as a result of a deamination process involving the radicals $\mathrm{OH}$ and $\mathrm{HO}_{2}$, which are formed in the primary radiation process according to ${ }^{4}$ :

$$
\mathrm{H}_{2} \mathrm{O} \sim \mathrm{M}^{\mathrm{O}} \mathrm{H}+\mathrm{OH}
$$

which in the presence of oxygen is followed by:

$$
\mathrm{H}+\mathrm{O}_{2} \rightarrow \mathrm{HO}_{2} \text {. }
$$

It may be expected that an attack by these radicals on the primary amino-groups $\left(-\mathrm{NH}_{2}\right)$ in the bases adenine, guanine and cytosine, and also in other amino-compounds, may, in addition, give rise to some hydroxylamine. By irradiation with X-rays of aqueous solutions of these bases, and also of their corresponding nucleosides and nucleotides, we have established that this process does, in fact, take place to some extent.

The presence of hydroxylamine was established by well-known colour reactions and also by a paperchromatographic method which was developed for this purpose. Quantitative determinations of the yields, for example, from adenine, show that doses of the order of $100,000 \mathrm{r}$. produce a concentration corresponding to about $1 \times 10^{-8} \mathrm{moles} /$ litre of hydroxylamine. However, only very small amounts are formed on irradiation of the nucleic acids. That the amino-group is the source of hydroxylamine is again demonstrated by the absence of this substance in irradiated solutions of, for example, hypoxanthine, uracil and uridine, in which cases no amino-groups are present.

Other compounds containing the primary aminogrouping have also been examined, and it has been found that hydroxylamine is produced in the irradia. tion of aqueous solutions of certain amino-acids (for example, alanine, lysine) and of certain amines (for example, ethylamine, histamine). In general, the yields of hydroxylamine depend markedly upon the $p H$ of the irradiated solutions.

These observations may be of biological significance in view of the possible formation of hydroxylamine in vivo from amino-compounds present in tissues, as it is well known that hydroxylamine is a strong cell poison and a very effective catalase inhibitor.

On the other hand, we found that irradiation of ammonia does not yield hydroxylamine. Irradiation of ammonium salt solutions with X-rays results predominantly in an oxidation to nitrite, a reaction which depends markedly on the hydroxyl ion concentration and which is also enhanced by the presence of molecular oxygen. This oxidation process is of interest in view of the corresponding process occurring in plants and in nitrifying bacteria.

GEORGE SCHOLES

King's College, University of Durham, Newcastle upon Tyne. Feb. 27.

${ }^{1}$ Stein, G., and Weiss, J., Nature, 162, 814 (1948); J. Chem. Soc., 3256 (1949). Dale, W. M., and Davis, J. V. Nature, 163, 64 (1949), Dale, W. M. Davis, J. V., and Gilbert, C. W., Biochem. J., 45,

${ }^{2}$ Scholes, G., and Weiss, J., Nature, 168, 640 (1950)

${ }^{3}$ Scholes, G., Stein, G., and Weiss, J., Nature, 164, 709 (1949).

- Weiss, J., Nature, 153, 748 (1944) ; Trans. Farad. Soc., 43, 314 (1947). 